\title{
LAS ESTRATEGIAS CONTRARREVOLUCIONARIAS EN LA ESCRITURA DE JACINTO V. DE MOLINA
}

\author{
Javier DE NAVASCUÉs \\ Universidad de Navarra
}

\begin{abstract}
Resumen: En el presente estudio se analizan las claves ideológicas de la obra de Jacinto V. de Molina, un escritor afrodescendiente y una figura excepcional en su época. Nacido en la frontera entre los imperios portugués y español, pasó la mayor parte de su vida en Montevideo. Sus escritos (nunca publicados en vida) abarcan un corpus vasto, y a veces caótico, de temas históricos, religiosos, filosóficos, jurídicos y autobiográficos. Molina se movió siempre entre diferentes contextos políticos, dedicó sus escritos a la defensa del Antiguo Régimen y trató de demostrar sus cualidades intelectuales en medio de una sociedad letrada blanca.
\end{abstract}

Palabras clave: Independencia, literatura uruguaya, afrodescendientes, escritura autobiográfica.

Abstract: This paper deals with Jacinto Ventura Molina's work and its ideological clues. Molina was an Afro-descendant writer and an exceptional figure in his time. He was born free in the frontier between Spanish and Portuguese Empires and lived and worked in Montevideo. His writings (not published during his life) show a vast and sometimes chaotic corpus with historical, religious, philosophical, juridical or autobiographical matters. Molina moved himself between different political contexts, devoted his writings to the apology of the Ancient Régime and he tried to demostrate his intellectual praises inside the white lettered society.

Keywords: independence, Uruguayan literature, afrodescendants, autobiographical writing.

Una visita a Montevideo debiera incluir una serie de paradas en las que, como en cualquier otra capital hispanoamericana, se reconocieran los lugares de la memoria republicana exaltados en la ciudad. Así, un paseo por la plaza Independencia obligaría al turista a fijarse en la majestuosa estatua ecuestre de José G. Artigas, centro simbólico de la plaza y de la misma independencia del país. Curiosamente, la confección de Artigas como "heroe máximo" de la revolución uruguaya fue un proceso que sólo culminó tiempo después de la muerte del 
caudillo ${ }^{1}$. Ignorado o denigrado por los dirigentes más caracterizados del siglo XIX, Artigas se vindica cuando la nación va buscando figuras individuales con las que constituir su identidad. De ahí que, por ejemplo, durante los festejos del centenario de 1911, se estimule la imagen de un Artigas como líder popular, valeroso caudillo rural que estableció las bases federales del país y unió a blancos y colorados ${ }^{2}$. Conviene recordar, además, que esta reinvención de un Artigas padre de la patria, conciliador de los extremos, incorporaba, con una función más retórica que real, una mayor sensibilidad hacia las minorías negras e indígenas. Éstas se sumaban a la iconografía de un líder para todos los uruguayos. En este sentido resulta más que elocuente el episodio de la "redota", o éxodo del pueblo oriental, en el que más de tres mil hombres, mujeres y niños, blancos y negros, fueron guiados por Artigas para continuar la lucha contra los españoles.

Lo cierto es que, en las luchas de Emancipación, los afrodescendientes cumplieron un destacado papel en toda Hispanoamérica. Movidos por las promesas de liberación futura, muchos soldados negros militaron en las filas patriotas y no es raro encontrarlos hoy en múltiples representaciones sobre las guerras de independencia ${ }^{3}$. Para el caso uruguayo, el negro más conocido es Joaquín Lenzina, "Ansina", fiel asistente de Artigas. El general Paz, en sus Memorias, lo recuerda cuando fue a visitar al prócer exiliado en Paraguay. Allí, Artigas "sólo tenía en compañía un negro, también anciano, que le acompañaba desde tiempos remotos y que me pareció ser oriundo de este país"4. Desde luego, la imagen semilengendaria de Ansina, militar y poeta, se asocia con la figura heroica del padre de la patria, caudillo popular y abierto a las minorías negras e indígenas en su proyecto de nación. Al propio Joaquín Lenzina, por cierto, se atribuyen composiciones patrióticas, en donde los charrúas son incluidos en el credo artiguista:

Los charrúas han vencido por igual

A los españoles y portugueses,

Que se metieron en la Banda Oriental:

A todos derrotaron varias veces.

A nadie respetan sino a Artigas.

Lo admiran por jinete valiente,

Porque no elude las fatigas,

Para que se respete a esta gente.

Según ellos es el Gran Cacique

Y le obedecen con devoción:

1 Así, P. Rocca ("La patria y la pluma”, Henciclopedia [sic], http://www.henciclopedia.org.uy/ autores/PabloRocca/PatriaPlumaI.htm, consltado 3/9/2011) señala la ausencia casi total de composiciones laudatorias de Artigas en la temprana antología poética La Patria y la Pluma.

2 C. Demasi, "La construcción de un héroe máximo: José Artigas en las conmemoraciones uruguayas de 1911”, Revista Iberoamericana, 213, 2005, 1029-1045.

3 Para una visión general de la participación de afrodescendientes en las luchas de la Emancipación, puede verse de G. Reid Andrews, Afrolatinoamérica, Madrid, Iberoamérica, 2007.

4 Cit. por E. M. Narancio, La independencia de Uruguay, Madrid, Mapfre, 1992, 224. 
Saben que así no habrá quien les quite

La libertad de su raza y nación ${ }^{5}$.

Sin embargo, pese a ese proyecto nacional en el que habrían participado todas las etnias orientales por igual, la realidad histórica ofrece algunos contrapuntos en donde la actuación de ciertos individuos acaba por mostrar un panorama más complejo. Frente a la visión algo simplista de una minoría entregada de forma homogénea a la causa artiguista, nos centraremos en la producción letrada de un representante notable de los afrodescendientes uruguayos, Jacinto Ventura de Molina, autor de una vasta, multiforme y, a veces, caótica obra. Para el presente trabajo nos basaremos tanto en sus textos editados hoy en día, como en otros consultados en la Biblioteca Nacional y el Archivo general de Montevideo, poco más de mil folios en total' .

\section{Una escritura a contracorriente}

Jacinto Ventura de Molina fue un hijo de libertos, nacido en Río Grande de San Pedro (actual Brasil) en 1766 y fallecido en Montevideo el 11 de agosto de 1841, un año antes de la abolición de la esclavitud en su país. Su producción puede considerarse como una de las pioneras de la literatura de Uruguay. Conviene advertir que Molina trata temas dispersos y agrupados, según Acree Jr. y Borucki, en varios núcleos: "Escritos históricos y autobiográficos" (la más numerosa), "Los afrodescendientes en los escritos de Molina", "Peticiones al poder", "Defensor de los pobres" y "Escritos políticos y literarios". Para entender la excepcionalidad del caso de Molina, hay que pensar en que la representación letrada de descendientes de africanos es minoritaria en el Río de la Plata ${ }^{7}$. De ahí

5 J. Lenzina, "Artigas y los charrúas", //www.chasque.net/vecinet/ansina32.htm (consultado 3/9/2011).

6 Citaremos principalmente los textos de Molina editados por Acree Jr. y Borucki en Los caminos de la escritura negra en el Río de la Plata, ed. de W. Acree y A. Borucki, Madrid, Iberoamericana, 2010, así como manuscritos inéditos que se encuentran en la Biblioteca Nacional de Montevideo (BN), divididos en tres tomos (T1, T2, y T3). En estos casos señalamos también el número del folio de cada tomo, además de regularizar la ortografía.

7 Sin embargo, como señala W. Acree Jr. ("Un letrado negro y el poder de la escritura", en J. V. de Molina, Los caminos de la escritura negra en el Rio de la Plata, ibid., 39-40) queda mucho todavía por rescatar de esta producción que se desarrolló entre las décadas de 1830 y 1870, es decir, de modo contemporáneo al proceso de la gauchesca. Hubo, además, una literatura abolicionista, sobre todo en fechas precedentes a las supresión de la esclavitud en Uruguay. A este tema concurrieron, por ejemplo, los orientales Adolfo Berro en El esclavo (1839) o Francisco Acuña de Figueroa en "La madre africana" "A la negrita Remedios". Ambos denunciaron el tráfico esclavista y el contrabando de personas que se producía en la frontera con Brasil (A. Borucki, Abolicionismo y tráfico de esclavos en Montevideo tras la fundación republicana (1829-1853), Montevideo, Biblioteca nacional, 2009, 102 y 142). Además, al igual que sucedió con el caso gauchesco, otras composiciones imitaban el habla bozal, como el Canto patriótico de los negros (1834) del mismo Acuña de Figueroa (véase el estudio de A. Gortázar, "Del aullido a la escritura. Voces negras en el imaginario nacional”, en H. Achúgar, ed., Derechos de memoria, Nación e independencia en América Latina, 
el interés de la reciente edición de sus múltiples escritos. Aunque se sabe que existían esclavos y libertos que podían leer y escribir, nunca hasta ahora se había tenido noticia impresa de una obra tan amplia de autor conocido ${ }^{8}$.

Las materias abordadas en los textos de Molina son muy variadas. Además de evocar su propia vida, vindica el oficio de las letras, realiza disquisiciones morales, debate sobre la legitimidad de la esclavitud, proclama el origen divino de la autoridad monárquica, etc. Muchos escritos suyos derivan de su oficio de escribano de las cofradías de negros en Montevideo. Valiéndose de su formación, tuvo que defender legalmente a sus hermanos de raza. Asimismo, también nos han llegado testamentos o litigios sobre separación de bienes redactados por él. Es poco probable que en la mayoría de sus escritos Molina pensara en los honores de la imprenta, salvo quizá lo que redactó para una extensa obra inédita, Glorias de la Santa Caridad de Montevideo. Durante mucho tiempo escribió sin que en Montevideo funcionara una imprenta (la primera es de 1807) y, después, la falta de sistema de sus textos hace pensar que escribiera para un reducido número de lectores, a veces con ánimo polémico, eso sí, pues suele dirigirse a los "Señores Filósofos", es decir, a los representantes del pensamiento ilustrado que él consideraba la causa de toda clase de desdichas personales y colectivas. Los Filósofos de Molina no eran otros, en definitiva, que los ideólogos criollos de la nueva nación en la que Molina no terminaba de acomodarse, como veremos. ¿Cuáles fueron, pues, los lectores de Molina? ¿Para quién escribía? Lo más seguro es que tuviera en mente a un lector criollo y letrado que le abriría una serie de puertas reservadas tan sólo a unos pocos. Al igual que sugiere Molloy ${ }^{9}$ respecto de la autobiografía del esclavo cubano Juan Francisco Manzano, Jacinto necesitó de la mediación del poderoso, no sólo para escribir, sino para ser leído. Si escribía, debía incorporarse a la institución letrada de los blancos. Ahora bien, a diferencia de Manzano, sus escritos no fueron manipulados o traducidos, es decir, no fueron utilizados de acuerdo con unos fines ideológicos determinados. Aunque Molina salga en defensa de sus hermanos de raza en varias ocasiones, no se preocupa demasiado en recordar padecimientos propios y vejaciones físicas, aunque las sufriese, sino, más bien, en esbozar un retrato superior de sí mismo que le permitiera acercarse a los notables de su tiempo. Por eso, insiste en las incomprensiones que genera su formación letrada o en sus cualidades intelectuales que le aúpan a un rango sobresaliente. La defensa de la vocación

Montevideo, Departamento de publicaciones de la FHCE, 2003). Por último, no olvidemos el presunto origen mulato de Bartolomé Hidalgo.

8 "En Buenos Aires y Montevideo hubo esclavos y libertos que habían aprendido a escribir con autorización o sin ella para cumplir sus trabajos y que dejaron evidencia en sus peticiones a los oficiales coloniales y luego al estado republicano" (Acree Jr., op. cit., 46).

9 S. Molloy, Acto de presencia. La escritura autobiográfica en Hispanoamérica, México, FCE, 1996, 55-56. 
intelectual es, para él, un móvil esencial de su escritura ${ }^{10}$. Y no ahorra esfuerzo en demostrar a sus lectores su autoconciencia de letrado. En cierta ocasión, por ejemplo, trata de demostrar la ubicación del Paraíso terrenal en tierras uruguayas y, para ello, evoca su erudición bíblica:

Nada dicté de las obras mentales de D. Josef de Molina, nada de su Balor, de su xenerocidad, Religión, Pulcritud, Prudencia, Jococidad y método político, afable, natural! La traducción latina S Sa Yo debo examinar con alguna particularidad a los señores teólogos, moralistas y filósofos, sino describiendo los físicos un lugar donde existe, este Paraíso evidente e incontestable. ¿Puedo yo usar de la reflexión de que lo hallé y mi fundada razón es que estaba regado, dice la escritura, de los grandes ríos: la misma escritura nos demuestra que el río Ganges no es mayor en cosa alguna que el río Paraná; que el Nilo sea más poderoso y extremo que el Uruguay; que el Tigris tenga más propiedad y extensión de mar que el Río de la Plata cuya riqueza de virtudes es siempre imponderable a causa de la suavidad particular de las provincias de San Felipe y Santiago de Montevideo; finalmente que el Eufrates conexiona con la virtud medicinal a las aguas del gran Río de Santa Lucía ${ }^{11}$.

Poco después de su "descubrimiento", acota que aquella región fue "nombrado Paraíso que por orden de Dios se traspuso a este continente sin serle concedido a otro que al humilde escritor J. de Molina"12. La modestia es, obviamente, retórica.

De sobra está decir que Molina no encajó en los moldes que su época reservaba a los individuos de su etnia y su clase social. Ciertamente fue soldado y trabajó de zapatero, es decir, ingresó en dos de los empleos, u oficios manuales, que se esperaban de un representante de la minoría de esclavos y libertos en el Uruguay de principios de siglo XIX. Sin embargo, su vocación letrada lo convirtió en un ser excepcional y él mismo no se recató en subrayarlo una y otra vez ${ }^{13}$.

\section{A la conquista del espacio letrado}

Como ya dijimos al comienzo, una parte muy amplia de los textos de Jacinto Ventura de Molina es de carácter autobiográfico. No es exagerado decir que en

10 Lo que no quiere decir que fuese indiferente a la cuestión, como se puede ver en Molina (Los caminos, op. cit., 270-272). Pero, incluso en estos textos, se advierte una especial sensibilidad hacia la privación de instrucción que suponía el hecho de la esclavitud.

11 Molina, BN, T1, fol. 1065.

12 Molina, BN, fol. 1065, t.1.

13 Montaño señala que los oficios más comunes en Montevideo eran los relacionados con el servicio doméstico o ciertos oficios como boyero, carrero, pescadero, camunguero, etc., además de soldado (O. D. Montaño, "Los afro-orientales. Breve reseña del aporte africano a la población uruguaya", en L. M. Martínez Montiel, coord., Presencia africana en Sudamérica, México, Consejo nacional para la cultura y las artes, 1995, 410-413). Esto apoya, claro está, los dos tópicos que se expresan en la literatura decimonónica rioplatense: el de siervo fiel o el de soldado de honor. 
buena parte de ellos subyace una apologia pro vita sua, como en tantas autobiografías de hombres públicos del XIX, con la particularidad del origen étnico del yo autobiográfico.

Habiendo el sabio presbítero Blanchard escrito su célebre y nunca bien ponderada Escuela de costumbres aconseja al género humano, y al hombre particularmente, la conservación de su honor, de su fama y de su honra. Porque este natural pensamiento, instruye de la propensión humana, el catón histórico: Procura conservar tu Honor, como el más precioso dote (sic) que nos dio la Naturaleza. Yo escribo en una época en que parece que los hombres ignoran, o han olvidado todo esto, publicando sus propios defectos y no disimulando los ajenos, si los tienen; o inventando hipérboles para superarlos y exponerlos a la crítica, al odio y a la vergüenza. ${ }^{14}$

Para llevar a cabo esa defensa de su persona y su vocación intelectual, Jacinto apela a varias estrategias. En primer lugar, acude a la dignificación de sus orígenes familiares. Así, su madre era una mujer trabajadora y limpia, aspecto éste último muy subrayado, pues sale al paso uno de los estereotipos más frecuentes sobre los negros. Más aún: a veces Jacinto pone especial énfasis en resaltar las virtudes de los individuos de su propia etnia. Refiriéndose a su madre, se pregunta" ¿Mas quien podra dictar que esta memoria sea pocible en una negra? Ydentica a todas las africanas, SSs Filosofos" ${ }^{15}$. Luego, escenifica su formación intelectual que bebe de las fuentes del pensamiento tradicional y defiende los valores ideológicos de la colonia. Para ello busca la protección de los poderosos a los que se dirige en ocasiones como lectores ideales - desde algunas figuras prominentes del Montevideo contemporáneo hasta el emperador de Brasil o el mismísimo Papa, a quien dirige una extensa epístola. En esa apelación al patrocinio de figuras de prestigio, sin duda Jacinto procuraba un apoyo a su inclinación intelectual, una pasión que, sin duda, le proporcionó desengaños e incomprensiones. Al final de su vida, algunos escritos suyos dan a entender su deseo de ascenso o reconocimiento social a toda costa (como cuando propone ser elegido abad de un monasterio sólo para negros).

Como antes apuntábamos, Jacinto V. de Molina fue hijo de libertos: Ventura de Molina y Juana del Sacramento. Según los datos autobiográficos que él mismo anota en sus escritos, su señor fue el militar español José de Molina, un importante lugarteniente del gobernador Pedro de Cevallos. Molina había llegado al Río de la Plata tras hacer carrera en Italia y se destacó en el sitio de Colonia de Sacramento (1762). Como capitán de caballería, tomó parte en la conquista de Río Grande un año después. El capitán Molina dio la libertad al padre de nuestro escritor como recompensa por salvarle éste la vida en un combate contra los portugueses. Y no sólo eso: don José se encargó de que recibiera

14 Molina, BN, T1, 1050.

15 Molina, en Acree Jr., 103. 
instrucción el pequeño Jacinto Ventura en la ciudad recién tomada al imperio luso. Así, a los seis años empezó a estudiar allí con el capellán José Galeano y más tarde con Mateo Cabral. En 1775 Río Grande es vuelto a ocupar por los portugueses y la familia debe trasladarse a la Banda oriental siguiendo a don José. En aquel tiempo el joven Jacinto acompaña a su venerado protector en distintas refriegas a lo largo de la frontera con las posesiones lusas: expedición de la sierra en 1773, combates en Río Grande (1775 y 1776), sitio de Colonia (1776), etc. El oficio militar al servicio de la corona española se convierte con el tiempo en timbre de orgullo para Jacinto Ventura de Molina, según se deduce de sus escritos y del retrato que disponemos de él. Allí se le representa, por cierto, vestido con casaca de oficial (en claro contraste con la imagen tópica del negro semidesnudo) y con unos anteojos levantados sobre la frente, signo del intelectual que siempre quiso ser. En efecto, desde siempre, en sus textos igual que en su retrato, Molina vela por consagrar una imagen elevada de sí mismo: las armas y las letras unidas en su persona.

Poco tiempo después de la llegada a Uruguay, la madre de Jacinto muere y don José toma personalmente bajo su protección al niño, acaso porque el padre en aquellos años lleva una vida desordenada. El español le enseña latín, según recuerda el propio Jacinto, y él es en buena medida responsable, no sólo de su formación letrada, sino del ideario tradicionalista que profesa el escritor uruguayo toda su vida:

¡Nada dicté de las obras mentales de D. Josef de Molina, nada de su Balor, de su xenerocidad, Religión, Pulcritud, Prudencia, Jococidad y método político, afable, natural! La traducción latina $S$ Sa palabra por palabra me la enseñó,e n quantos libros latinos usaba el dijesto, o cartilla de leyes, de onse años, yo de oir toda su lectura, e instrucción, a SSa la doctrina de Bayadolid, sobre la de Astete, la devi a $S S^{a}[\ldots]$

La Doctrina de Dn Josef de Molina me descubrio el Origen del Ombre, la Causa, y Remedio de su corrupción y miseria, el fin para que esta destinado [...] una doctrina que contiene la moral más Pura, Sublime y propia para mi felicidad, la de los particulares y la de la Sociedad, es la doctrina que me enseñó Dn Josef de Molina ${ }^{16}$.

Como se ve una y otra vez en los escritos de Jacinto, éste siempre sintió una profunda fidelidad hacia su antiguo señor y hacia el ideario que recibió de él, lo que le acarreará numerosos problemas con las autoridades republicanas, nuevos garantes de un orden al que Molina le costó adaptarse.

En cualquier caso, en el mismo año de 1782 mueren su padre y su protector ${ }^{17}$. Jacinto se ve entonces solo en el mundo y se dedica al oficio de zapatero,

16 Molina, en Acree Jr. y Borucki, op. cit., 108.

17 A. Gortázar conjetura que el verdadero padre de Jacinto fuera realmente don José (véase de A. Gortázar, El licenciado negro: Jacinto Ventura de Molina, Montevideo, Trilce, 2007). El propio 
que compagina con su afán por la escritura. A los 22 años contrae matrimonio con Rufina Campana. Por los datos que nos proporciona en sus escritos, fue un matrimonio feliz. En 1806 deben mudarse a la población de Guadalupe (hoy Canelones) debido a problemas de salud de Rufina. Sin embargo, vuelven a la futura capital de Uruguay para 1814. Jacinto se verá seriamente afectado durante la ocupación de Montevideo.

Su esposa siempre se sintió orgullosa de la vocación intelectual de Jacinto, uno de sus leit motive redundantes. Según vamos repasando, Molina vuelve una y otra vez sobre la dignidad de su pasión por la escritura que, en su caso, es aún más extraordinaria, debido al color de su piel. Rufina protagoniza algunas escenas importantes de su biografía. Así, por ejemplo, ella actúa en dos ocasiones para salvar la vida de Jacinto. En la primera quema escritos que ella piensa pueden ser comprometedores durante la invasión inglesa de 1806. De esta forma, es presumible que Jacinto hubiera guardado escritos de tema militar en los años anteriores, pero se han perdido todos. En la segunda ocasión, en 1814, la esposa ruega a las autoridades artiguistas que suelten a Jacinto, torturado y encerrado en un cepo por negarse a formar parte de las fuerzas patriotas. En esta ocasión pierde el puesto de teniente de negros, grado obtenido durante su ejercicio junto a las tropas españolas. Rufina muere en 1819.

Las cosas cambian para Jacinto con la invasión de las tropas portuguesas en 1816 ${ }^{18}$. "Para un católico monárquico y antiartiguista como él, la llegada de las tropas brasileñas representó nada más que la restauración de un orden colonial del que era producto"19. Molina cuenta en un texto manuscrito que pide entrevistarse con Federico Lecor, barón de la Laguna comandante del ejercito conquistador, a fin de que se le repongan los méritos perdidos durante la ocupación de Artigas. Como señala Gortázar con agudeza ${ }^{20}$, este texto delata el interés del autor en mostrar su conocimiento superior (en este caso, de la lengua portuguesa), además de resaltar su dignidad personal una vez más. La ocupación de Lecor devolvió provisionalmente a Jacinto al mundo legitimista en el que se había criado. En aquellos tiempos de desconcierto, cuando la Banda oriental

Jacinto comenta que la "muger clandestina" del militar español, Catalina Gil, tenía celos de su madre, debido al buen trato que recibía de don José. Sin embargo, Jacinto es de la opinión de que era un infundio y que los celos fueron motivo de chacota entre don José y sus compañeros. Acree Jr. piensa que no hay pruebas suficientes para afirmar la paternidad de don José y que, además, si Jacinto hubiera albergado alguna sospecha, se hubiera acogido a ella, debido al superior estatus social que suponía el tener sangre "blanqueada" (W. Acree Jr., "Jacinto Ventura de Molina. A Black Letrado in a White World of Letters, 1766-1841", Latin American Research Review, 44, 2009, 37-58).

18 A finales de 1816 las tropas lusobrasileñas al mando de Carlos Federico Lecor tomaron la fortaleza de Santa Teresa y, poco después, en enero de 1817, entraron en Montevideo. Aunque los planes de Lecor pasaban por incorporar la Banda oriental a la corona portuguesa, muchos seguidores del bando español vieron con esperanza su actuación al haber derrotado a los artiguistas.

19 Gortázar, El licenciado negro, op. cit., 16.

20 Ibid., 46-47- 
cambiaba de manos continuamente, la llegada de tropas relacionadas con el Antiguo Régimen, aunque fueran de los antiguos enemigos de su fallecido protector, le permitió reconocer una autoridad que podía reconocer de acuerdo con su ideario providencialista. Precisamente por esa familiaridad con el orden imperial, Molina no parecía sentir incomodidad con algunos aspectos menos amables con su propia etnia, como la supresión de la Ley de vientres de 1813. En realidad, formó parte de los seguidores de Lecor, incluso cuando éste marchó a la localidad de Guadalupe en 1823 para continuar la guerra. Los escritos de esa época así lo atestiguan. Durante la invasión brasileña, Jacinto dirige escritos a Lecor o a los emperadores de Brasil y, así, en 1821 sostiene que le fue otorgado el título de "Licenciado en Reales Derechos" por el mismísimo Juan VI de Portugal. No es de extrañar que Molina se sienta entonces cómodo con el régimen y que, en un esfuerzo de síntesis, abogue en un escrito por la unión de las casas reales de Braganza y Borbón ${ }^{21}$. La coalición de las dos monarquías era, desde su punto de vista, el mejor modo de defenderse de unas ideologías nuevas que, para él, eran disolventes y anticatólicas.

De todas formas, cuando se consolide la independencia de Uruguay, el nuevo estado acaba por concederle su título de licenciado. Este último período de su vida se caracteriza por las dificultades con que Molina debe afrontar la nueva social política y social. Tiene que integrarse, pero su lealtad a los antiguos señores no le permite el tránsito fácil que otros han hecho ${ }^{22}$. En los años treinta se relaciona con Joaquín de la Sagra, un español que combatió con los realistas, fue funcionario del gobierno de Lecor y acabó participando en una logia masónica. De la Sagra fue miembro de la Hermandad del Hospital de la Caridad y, por su mediación, Molina empezó a escribir las Glorias de la Caridad de Montevideo. Igual que Tomás García de Zúñiga, otro prohombre de Lecor con quien terminó enemistado Molina, de la Sagra fue uno de los contactos en las élites montevideanas que nuestro autor buscó a fin de dar rienda a su vocación intelectual y a su afán de situarse socialmente. En esos años también participa como abogado defensor de negros. Aquí, siempre da testimonio de su horror frente a disturbios o perturbaciones del orden heredado. En 1833 se desarticuló en Montevideo una conspiración de esclavos y libertos. Félix Laserna, su líder, y un instigador alemán, Guillermo Guitarner, fueron condenados a la cárcel. Asimismo, se prohibieron todas las reuniones de sociedades negras intramuros de Montevideo. Molina pidió entonces en una "Oración política y moral" dirigida a la cámara de representantes del país que se levantase la prohibición. Después de

21 Molina, Los caminos, op. cit., 219.

22 Así, por ejemplo, se queja en carta al emperador de Brasil de la independencia de Uruguay: "E1 Todo poderoso conoce mi corazón y mis más diminutos pensamientos cuya conclusión descubre que V.M.Y. no puede desentenderse y abandonar esta Provincia, sin el más orroroso crimen" (Molina, ibid., 282). 
manifestar su repugnancia ante cualquier conspiración libertaria ${ }^{23}$, su argumentación se basó en la "natural" fidelidad del negro hacia sus señores y no dudó en acudir a ejemplos extraídos de la época colonial ${ }^{24}$.

Así pues, Molina no fue indiferente a la condición de sus hermanos de raza, pero su discurso adolece de contradicciones. De un lado, se muestra defensor de la igualdad natural de todos los individuos, pero, en otros lugares su argumentación retrocede, en buena medida debido a su adhesión al Antiguo Régimen y a la índole del lector ideal al que dirige sus escritos. Así, llega a disculpar a los reyes de España que, según él, desconocían la existencia de la institución esclavista en el Nuevo Mundo. En otro pasaje todavía más contradictorio atenúa las críticas a la desigualdad, después de haberla denunciado:

Los varios filósofos que, conviviendo con solo su humor, definen a los negros, según las ideas que les presenta la novedad y la experiencia, jamás admiten que la razón de las ventajas de los señores blancos, nace del trato y de la instrucción, cuyo defecto ha hecho siempre despreciable la de este color.

¡Pero, ¿cómo yo no puedo, o debo criticar la voluntad del Criador? ¡Si debo serle agradecido! No se me debe motejar, que deseo dar a Su Majestad Infinita, Lauro, Alabanza y Honor. Esta razón y la de atención a esta Santa caridad, ponen en mano de VS.S. esta obra en prueba de obligación con que me distinguió la Infinita providencia por las Augustas manos y Voluntad de los Monarcas ${ }^{25}$.

Ese V.S.S. es siempre un criollo o europeo poderosos. En otra carta, ésta dirigida al rey de Portugal y a Federico Lecor, comandante en jefe de las fuerzas ocupantes lusobrasileñas, detalla cuáles son sus ideas para la instrucción de los afrodescendientes en la Provincia Cisplatina. El siguiente párrafo es un ejemplo del proyecto paternalista que Molina propone para sus hermanos de raza, así como de las ideas conservadoras en las que basa su discurso:

S.M.y V.E. [el emperador y Lecor respectivamente) deben concederme que este método literario de mis reflexiones hace muchas ventajas a los historiadores presentes que han estado en el país o países donde existen: nacieron, o de criaron, no detallen sus particularidades, y cuando más de un modo que no puede formarse idea. De parecer donde la población es la suma falta, y tan pingüe y fértil provincia. Y es contraria mi idea moral de población a la filosófica, con que favorecen hoy los monarcas de la nación inglesa, a los etíopes de la Guinea, admitiendo toda suerte de luces para los negros, excepto la religión y el Evangelio. Por principio absoluto yo sólo admito para las poblaciones de esta provincia la religión y el Evangelio, y de modo alguno la filosofía. Las conclusiones de ambos métodos se demostrarán dentro de un siglo. Sabios y fuertes los etíopes, pero también infieles. ¡Cuánto la provincia de Montevideo poblada demostrará por sus

23 Ibid. 150.

24 Ibid. 154-156.

25 Molina, BN, T3, fol. 114. 
principios! Sabios filósofos, pero grandes Santos: efecto de su principios: ningún teólogo o moralista puede más que ser ilustrado por la filosofía. Un filósofo puramente filósofo no puede destruir sus preocupaciones y costumbres, por todas las luces de la moral y dogmas teológicos. En suma: Inglaterra dicta y enseña como protestante. Portugal, como católico ${ }^{26}$.

\section{Conclusiones}

Sin duda la formación de Molina fue sobresaliente para la región del mundo, la época y el origen social que le tocaron en suerte. De entrada, leyó la biblioteca de su protector, hombre medianamente letrado; asimismo, la esposa de un comandante español en Montevideo, Francisca Ortega, le regaló parte de su biblioteca cuando ella abandonó la ciudad. En sus escritos se citan autores clásicos y modernos: Luciano, Santo Tomás de Aquino, la Biblia, textos apócrifos cristianos, padres de la Iglesia, Juan de Solórzano, Grocio, el P. Feijoo, Voltaire, Rousseau, Montesquieu, etc. Es muy probable que la mayor parte de estos testimonios los conociera de segunda mano. Su formación adolecía inevitablemente de desorden y su acceso a la cultura letrada se revela muchas veces como insuficiente. Así, se detectan lagunas y errores, como cuando atribuye a Calderón los versos de "Ven, muerte tan escondida" del Comendador Escrivá. Por lo demás, sus opciones filosóficas, políticas y jurídicas se orientan hacia la defensa de los valores del Antiguo Régimen. Con escrupulosidad apela a argumentos teológicos para fundar su crítica a la nueva situación política nacida de las guerras de independencia. Con este bagaje intelectual, del que hace Molina continuas protestas de lealtad, difícilmente podía integrarse en la nueva comunidad uruguaya, nacida al calor de una Modernidad que destruiría la legitimidad de las monarquías de derecho divino 27.

Al mismo tiempo, sin embargo, no deja de ser consciente de lo inusitado de su posición, aun dentro del esquema ideológico que dice defender. Para resolver la contradicción, acude a razonamientos teológicos que imponen la igualdad entre todos los seres humanos sin distinción de raza: “... porque los señores blancos vuelan como los pájaros o nadan como los peces, escriben casi naturalmente. Los negros no. Aunque, gracias a Dios, somos hombres como ellos, redimidos por la preciosísima sangre de Nuestro Señor Jesucristo, y, si los blancos desean que nos salvemos, nosotros deseamos igualmente que se salven ellos" 28 . No deja de ser ingenioso el modo con que, en esta cita, Molina revela la igualdad de todos, blancos y negros, como hijos de Dios, al mismo tiempo que salva, implícitamente, su identidad individual al sugerir en él una excepción dentro de

${ }^{26}$ Molina, BN, T3, fol. 58.

27 Según Anderson, las naciones del siglo XIX y XX se definen por ser comunidades imaginadas como inherentemente limitadas y soberanas, es decir, sin sujeción a otra soberanía que al Estado moderno (B. Anderson, Comunidades imaginadas. Refexiones sobre el origen y la difusión del nacionalismo, México, FCE, 2006, 23-25).

28 Molina, en Gortázar, El licenciado negro, op. cit., 53. 
los afrodescendientes. Así sucederá, de una forma u otra, en otros lugares de su producción, en donde el autor quiere dejar claro su carácter extraordinario ante un lector blanco.

En efecto: gran parte de su obra, como tantas autobiografías de hombres públicos del siglo XIX, está en función de la reivindicación de sí mismo como figura sobresaliente. Molina quiere ser un letrado en el sentido que Rama da al término ${ }^{29}$, pero su origen subalterno le otorga un matiz especial a esta denominación. Es verdad que la posesión de la escritura le hace consciente de tener un arma superior dentro de los de su propia etnia y, en cierta forma, le permite acercarse a los grupos dominantes. Sin embargo, para acceder a la categoría de hombre público y respetado por sus cualidades intelectuales, tiene que afrontar el desprecio de muchos ${ }^{30}$, lo que acentúa, sin duda, la carga retórica con que se refiere a sí mismo en sus escritos. Desde las protestas de humildad que persiguen captar la benevolencia del lector hasta la exageración de sus méritos, todo confluye a la representación de sí mismo como ser excepcional. Las continuas y admirativas referencias a su protector español pueden leerse como un refrendo de este programa de glorificación individual. Engrandeciendo a su "padre" intelectual, Molina se engrandece a sí mismo, sobreponiéndose a los de su condición. En algún momento, hasta su nacimiento es reinterpretado como una señal providencial por la cual don José de Molina, su gran protector, serviría al mundo.

Un aspecto digno de estudiarse con mayor detenimiento es el contexto comunicativo en el que Molina situó sus escritos. Todos sus textos manifiestan un receptor que se encuentra en una posición de superioridad que el narrador tiene en consideración una y otra vez. En ocasiones, se trata de un enemigo - los "filósofos" hacia los que se dirige en tono de defensa y reprochando la elocuente "mordacidad" de ellos; en otras, es un poderoso al que solicita un beneficio para él o su comunidad. En este contexto, el "lector ideal" de Molina forma parte de un grupo integrado por generales, emperadores o incluso autoridades eclesiásticas ${ }^{31}$. Particular interés tiene, en este sentido, la carta al Papa Gregorio XVI en el que pide apoyo para la erección de una abadía que habría de llamarse de

29 Á. Rama, La ciudad letrada, Montevideo, Arca, 1998.

30 Así, el anónimo cruel que se adjunta en sus propios escritos: Aparta negro, loco y asqueroso,/No seas impertinente y majadero,/Trabaja en tu oficio de zapatero/ No seas holgazán y perezoso:/ Dejate de escribir temeridades/ Que no sirven a todos/ más que de gran risa/ Un amigo que te ama te lo avisa, A ver si así enmiendas tus barbaridades (en Molina, Los caminos, op. cit., 234).

31 Señala Molloy que el autor de autobiografía hispanoamericana en el siglo XIX carece ya de legitimación institucional (Iglesia, o Corona). Ya no se escribe por encargo de éstos, sino por otros motivos. "Si ya no se escribe para el Rey ni para la Iglesia, ¿para quién se escribe?, ¿Para la verdad? ¿Para la verdad? ¿Para la historia...?” (Molloy, op. cit., 14). En consecuencia, el vacío de autoridad genera un yo en crisis que se enfrenta a la tensión entre su actuación pública y la privada, entre sujeto y patria, etc. Molina, sin duda, constituye un caso interesante, puesto manifiesta, en algunos de sus escritos, un interlocutor colonial, para el que escribe por encargo, al mismo tiempo que se desprende en él una voluntad de afirmación pública propia de su siglo. 
María Rufina Campana, en honor de su esposa fallecida en 1819. Este convento debía ubicarse en Montevideo que, según Molina, había sido arrasada como ciudad católica por los asedios que destruyeron sus templos, y por la política laicista de sus gobernantes. Como en otros textos suyos, arremete contra las novedades filosóficas, que él da por heréticas y equivocadas fatalmente por culpa de Diderot, Voltaire y Rousseau. El resultado, en fin, era que Montevideo carecía de clero diocesano digno de tal nombre y, para paliar la situación, Molina propone la creación de un convento sólo compuesto de afrodescendientes. Lo que pretende, pues, el autor es "ver si puedo salbar ese pueblo yncognito negro" 32 , y para ello solicita, con audacia e ingenuidad, ser ordenado sacerdote por Su Santidad $^{33}$. Necesariamente tiene entonces que acudir a sus propios méritos. Allî proclama su carácter sobresaliente entre los de su raza, a la que considera desgraciada, más ignorada incluso en América que en Europa. Molina reconoce las limitaciones de la etnia africana como medio para favorecerse él mismo. Marca así su condición de ser excepcional:

Mi color negro, mi estado particular - indigente - eccigen para mi la singular gracia del sacerdocio, y merecer en el mi fin feliz. Exemplar a los de mi color en los principios de mi educación, en los medios de comportacion, estudio $\mathrm{y}$ refleccion, $\mathrm{y}$ en los efectos. Quando se ygnora, que en todo el mundo antiguo. Algun negro aya dictado, discurrido o creado alguna cosa que el comun sentir de los ombres acienta las proporciones naturales del obgeto que se propuso ${ }^{34}$.

Jacinto Ventura de Molina rompió con su vida los estereotipos sobre los individuos de su clase. No sobresalió por su afición al baile ni se sometió en exclusiva a los oficios manuales que la sociedad criolla había adjudicado a la gente de su color. Nunca fue un fiel soldado de la república naciente, aunque sí de la $\mathrm{Co}^{-}$ rona; no destacó como sirviente de criollos, pero se jactó de haberlo sido de un funcionario imperial y desafió las convenciones de su época al tratar a las élites de tú a tú, aunque hiciera continuas protestas de humildad en sus escritos. Intentó destacar en un camino, el de la escritura, reservado a los blancos pudientes. Y por distintos medios - estrategias acordes con su ideario contrarrevolucionario- se humilló y se ensalzó por la letra, confiado en una visión del mundo en retroceso, en conflicto directo con la ideología liberal que se instalaba sin remedio a su alrededor.

\section{BIBLIOGRAFÍA}

Acree Jr., W., "Jacinto Ventura de Molina. A Black Letrado in a White World of Letters, 1766-1841", Latin American Research Review, 44, 2009, 37-58.

32 Molina, Los caminos, op. cit., 186.

$33 \mathrm{O}$ es, tal vez, una estrategia más para postularse como interlocutor de un receptor de prestigio, frente a los lectores habituales, entre los que aspiraba a conquistar un espacio.

34 Ibid., 188. 
—, "Un letrado negro y el poder de la escritura", en J. V. de Molina, Los caminos de la escritura negra en el Río de la Plata, ed. de W. Acree y A. Borucki, Madrid, Iberoamericana, 2010, 39-58.

Anderson, B., Comunidades imaginadas. Reflexiones sobre el origen y la difusión del nacionalismo, México, FCE, 2006.

Barrios, M., A. Gortázar y A. Pitetta, eds., Jacinto V. de Molina. Antología de manuscritos (1817-1837), Montevideo, FHCE/CSIC, 2008.

Borucki, A., Abolicionismo y tráfico de esclavos en Montevideo tras la fundación republicana (1829-1853), Montevideo, Biblioteca nacional, 2009.

Demasi, C., "La construcción de un héroe máximo: José Artigas en las conmemoraciones uruguayas de 1911”, Revista Iberoamericana, 213, 2005, 1029-1045.

Gortázar, A., "Del aullido a la escritura. Voces negras en el imaginario nacional", en H. Achúgar, ed., Derechos de memoria, Nación e independencia en América Latina, Montevideo, Departamento de publicaciones de la FHCE, 2003.

—,El licenciado negro: Jacinto Ventura de Molina, Montevideo, Trilce, 2007.

Molina, J. V. DE, Los caminos de la escritura negra en el Río de la Plata, ed. de W. Acree y A. Borucki, Madrid, Iberoamericana, 2010.

- (BN), Escritos, Biblioteca nacional, sala de materiales antiguos, Montevideo.

Molloy, S., Acto de presencia. La escritura autobiográfica en Hispanoamérica, México, FCE, 1996.

Montaño, O. D., "Los afro-orientales. Breve reseña del aporte africano a la población uruguaya”, en Luz María Martínez Montiel, coord., Presencia africana en Sudamérica, México, Consejo nacional para la cultura y las artes, 1995, 391-449.

Rama, A., La ciudad letrada, Montevideo, Arca, 1998.

Reid Andrews, G., Afrolatinoamérica, Madrid, Iberoamérica, 2007.

RoccA, P., "La patria y la pluma”, Henciclopedia [sic], http://www.henciclopedia.org.uy/ autores/PabloRocca/PatriaPlumaI.htm (consultado 3/09/2011). 